\title{
Coseismic displacement due to the 2008 Iwate-Miyagi Nairiku earthquake detected by ALOS/PALSAR: preliminary results
}

\author{
Youichiro Takada ${ }^{1}$, Tomokazu Kobayashi ${ }^{2}$, Masato Furuya $^{1}$, and Makoto Murakami ${ }^{2}$ \\ ${ }^{1}$ Department of Natural History Sciences, Hokkaido University, Sapporo, Japan \\ ${ }^{2}$ Institute of Seismology and Volcanology, Hokkaido University, Sapporo, Japan
}

(Received October 9, 2008; Revised January 29, 2009; Accepted February 12, 2009; Online published March 12, 2009)

\begin{abstract}
Applying interferometric SAR (InSAR) analysis to the 2008 Iwate-Miyagi Nairiku earthquake, we detected notable ground displacements of several tens of centimeters to about $1.2 \mathrm{~m}$ that extend further south of the epicentral area. We explained the InSAR data by constructing a fault model consisting of four WNW dipping and one ESE dipping reverse faults. The residuals between observed and modeled deformation are less than $6 \mathrm{~cm}$ in most of the area, which is comparable to the errors caused by atmospheric effect. To fill the lack of InSAR data in the hypocentral area, we applied a pixel matching technique to the intensity images, which shows a shortening in range offsets by as much as $\sim 2 \mathrm{~m}$ along a narrow zone stretching along the eastern foot of Mt. Kurikoma, indicating a localized uplift. We also found remarkable contrasts in the range offsets around the low coherence area equivalent to a very large displacement gradient to the WNW of the hypocentral area as well as ESE. We conclude that the main faulting occurred on the WNW dipping reverse faults, but that the overall geometry of the fault system is quite complex including at least one conjugate faulting, as also supported by the hypocentral distribution of aftershocks.
\end{abstract}

Key words: 2008 Iwate-Miyagi Nairiku earthquake, pixel offset field, stereoscopic effect, complex fault structure.

\section{Introduction}

On 14 June 2008, a $M_{\mathrm{j}} 7.2$ earthquake struck northeast Japan. The epicenter was to the northeast of Mt. Kurikoma, an active volcano (Fig. 1). To the northeast of the epicenter, only one west dipping thrust fault (Dedana fault) is known to be active (Fig. 1). We obtained the overall ground displacement field associated with the earthquake using two complementary data sets: phase change maps from interferometric synthetic aperture radar (InSAR) and range offsets maps from the amplitude correlation of SAR images. The purpose of this study is to clarify the fault configuration by constructing a fault model that can explain the SAR data. For this purpose, we used the InSAR data to constrain the fault geometry and coseismic slip and discuss the results in view of the range offsets. We modeled the fault system using several small fault rectangles having uniform slip rather than one large fault (i.e., only one geometry) with much freedom in the slip distribution.

\section{InSAR Data Analysis}

We processed ALOS/PALSAR data by Gamma software (Wegmüler and Werner, 1997). For the ascending orbit (Fig. 2(a)), we chose the data acquired on 21 June 2007 and 23 June 2008 because of the shortest perpendicular baseline $(-303 \mathrm{~m})$. For the descending orbit (Fig. 2(b)), we used the data acquired on 29 August 2007 and 16 July 2008

Copy right(c) The Society of Geomagnetism and Earth, Planetary and Space Sciences (SGEPSS); The Seismological Society of Japan; The Volcanological Society of Japan; The Geodetic Society of Japan; The Japanese Society for Planetary Sciences; TERRAPUB because both of data sets were acquired by fine resolution mode (perpendicular baseline is $-774 \mathrm{~m}$ ). All of these data were taken with an off-nadir angle of 34.3 degree. Little ionospheric effect can be found in those interferograms. We also corrected for the residual phase assuming a linear elevation dependence of the atmospheric phase delay. Figures 2(a) and (b) show a wide area of coherence loss even with L-band sensor of ALOS/PALSAR.

This earthquake took place in a mountainous area where differences in elevation caused large artifacts in the pixel offsets due to a slight difference in satellite positions before and after the earthquake (stereoscopic effect) (Michel et al., 1999). We removed this artifact by elevation-dependent coregistration fully incorporating a $50 \mathrm{~m}$ mesh digital elevation map provided by the Geographical Survey Institute of Japan.

Both the ascending and descending images indicate remarkable range changes in the radar line-of-sight direction $(\Delta \mathrm{LOS})$ to the south of the epicentral area (Fig. 2(a, b)), where the opposite signs of $\triangle \mathrm{LOS}$ across the hypocentral area indicate that the WNW-ESE horizontal convergent motion dominates in the LOS interferometric signal. In the ascending image, the $\triangle$ LOS spans from $115 \mathrm{~cm}$ away from the satellite around the summit of Mt. Kurikoma to about $75 \mathrm{~cm}$ toward the satellite around the eastern foot of the mountain.

\section{Fault Modeling}

We constructed a fault model consisting of five rectangular faults with uniform slip. To minimize the effect of 
Table 1. Fault parameters of our preferred model. We define the location of each fault as its center. The unit of length, width, and depth are in kilometers. Dip, strike, and slip angle are in degrees, and slip is in meters. $M_{\mathrm{w}}$ is the equivalent moment magnitude. We adopted the convention defined by Aki and Richards (1980).

\begin{tabular}{cccccccccccc}
\hline Fault & Longitude & Latitude & Length & Width & Depth & Dip & Strike & Slip angle & Slip & $M_{\mathrm{w}}$ \\
\hline F1 & 140.90 & 39.12 & 9.0 & 5.0 & 4.0 & 27.0 & 190 & 80 & 1.5 & 6.1 \\
F2 & 140.895 & 39.04 & 8.5 & 6.8 & 2.3 & 37.5 & 180 & 76 & 3.0 & 6.4 & 71 \\
F3 & 140.85 & 38.99 & 10.0 & 6.5 & 2.6 & 53.0 & 355 & 2.1 & 6.3 \\
F4 & 140.854 & 38.94 & 10.2 & 6.5 & 2.2 & 30.0 & 200 & 62 & 6.4 & 6.7 \\
F5 & 140.79 & 38.85 & 7.5 & 3.0 & 2.3 & 55.0 & 200 & 80 & 2.0 & 6.0 \\
\hline
\end{tabular}

orbit estimation error and atmospheric noise, we limited the modeled region to the proximity of the hypocenter. We first found plausible ranges of each fault parameter by a trialand-error forward modeling approach, and then adopted a grid-search approach to obtain the preferable fault parameters. Figures 2(c) and (d) indicate the synthetic $\triangle$ LOS calculated by an elastic half-space dislocation model (Okada, 1992). Considering the high heat flow and shallow depth of the hypocenter, we take the rigidity as $30 \mathrm{GPa}$. The preferred fault parameters and moment releases are listed in Table 1. The total seismic moment and its equivalent moment magnitude are $2.54 \times 10^{19} \mathrm{~N} \mathrm{~m}$ and $\sim 6.9$, respectively. Among the five faults, four dip towards WNW and one dips ESE, which means our model suggests a conjugate faulting near the epicentral area. All the faults have relatively larger dip-slip components than the left lateral components (Fig. 2(c, d) and Table 1). The residuals from the observed interferograms are shown in Fig. 2(e, f) in which our model explains the observation except for the very narrow zone surrounding the low coherence area. The residuals are less than $6 \mathrm{~cm}$ in most area, which is comparable to the errors caused by atmospheric effect. According to our model, there should be a large uplift zone above each fault patches trending along the eastern foot of the Mt. Kurikoma. We discuss the plausibility of our model inside the hypocentral area in the next section.

\section{Discussion and Conclusions}

Interferometric coherence was significantly lost in the proximity of the hypocentral area (Fig. 2). To elucidate the ground displacement there, we applied a pixel matching technique to the intensity images created from SAR data (e.g., Tobita et al., 2001; Pathier et al., 2006).

The results show a large negative offset in range direction up to $2 \mathrm{~m}$ for both the ascending and descending data in a narrow zone stretching in the $\mathrm{N}-\mathrm{S}$ direction along the eastern foot of Mt. Kurikoma (Fig. 3), which means a localized uplift in the hypocentral area. The localized uplift area coincides very well with the low-coherence area in the InSAR images of Fig. 2. Therefore, we may attribute the low-coherence to the strong displacement gradient associated with the significant uplift due to the fault motion just below there.

It should be noted that there are remarkable contrasts in the range offsets to the WNW (Fig. 3(a)) and ESE (Fig. 3(b)) of the hypocentral area equivalent to a very large displacement gradient, which supports the existence of the ESE dipping fault in our fault model (F3 in Fig. 2(c, d)) as well as four WNW dipping faults. The range offsets calcu-

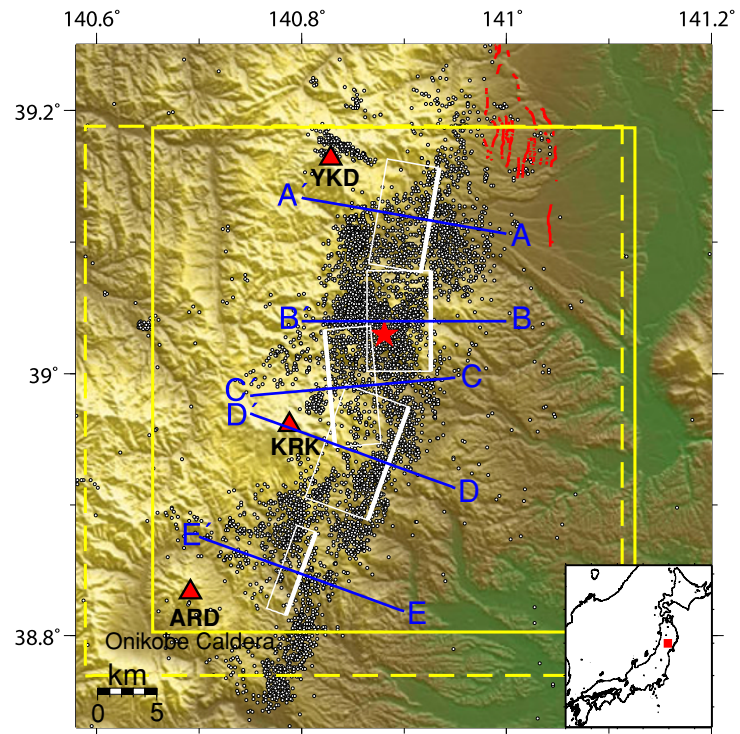

Fig. 1. Tectonic setting. Inset shows studied area (red rectangle). Red star indicates epicenter of the main-shock determined by the National Research Institute for Earth Sciences and Disaster Prevention (NIED). White circles indicate epicenters of earthquakes during 14 June to 18 September 2008 provided by the Japan Meteorological Agency (JMA). White frames indicate surface projections of the faults proposed in this study. Thick white lines indicate the upper edges. Yellow solid and broken frames show the areas acquired by ascending and descending orbit in Figs. 2 and 3, respectively. Blue lines indicate the section lines for each figure of Fig. 4. Red lines indicate surface traces of the Dedana fault system (Nakata and Imaizumi, 2002). YKD: Mt. Yakeishi, KRK: Mt. Kurikoma, ARD: Mt. Arao.

lated from our model (Fig. 3(c, d)) show similar patterns to the observations. We need to reduce the error in the range offsets in the future to check if each fault segment of our model is more continuous. Figure 4 shows the depth cross-sections of hypocenters provided by the JMA, which suggests variable fault configurations in the aftershock area. The hypocenters are a bit deeper than the fault model, but those recently relocated by Okada et al. (2008) are shallower and consistent with our fault model. In the northern sections ( $\mathrm{BB}^{\prime}$ to $\mathrm{CC}^{\prime}$ in Fig. 4), we can identify two fault planes, of which one dips to the east and another to the west, which is consistent with conjugate faulting expressed as F2 and F3 in our model. As can be seen in the southern part $\left(\mathrm{EE}^{\prime}\right)$, the depth gets much shallower than the northern part and the hypocentral distribution have no outstanding characteristic. The plan view of epicenter in Fig. 1 shows few earthquakes around the geothermal area like Mt. Kurikoma and the Onikobe caldera. The combination of a low seismicity level and a low interferometric coherence would im- 


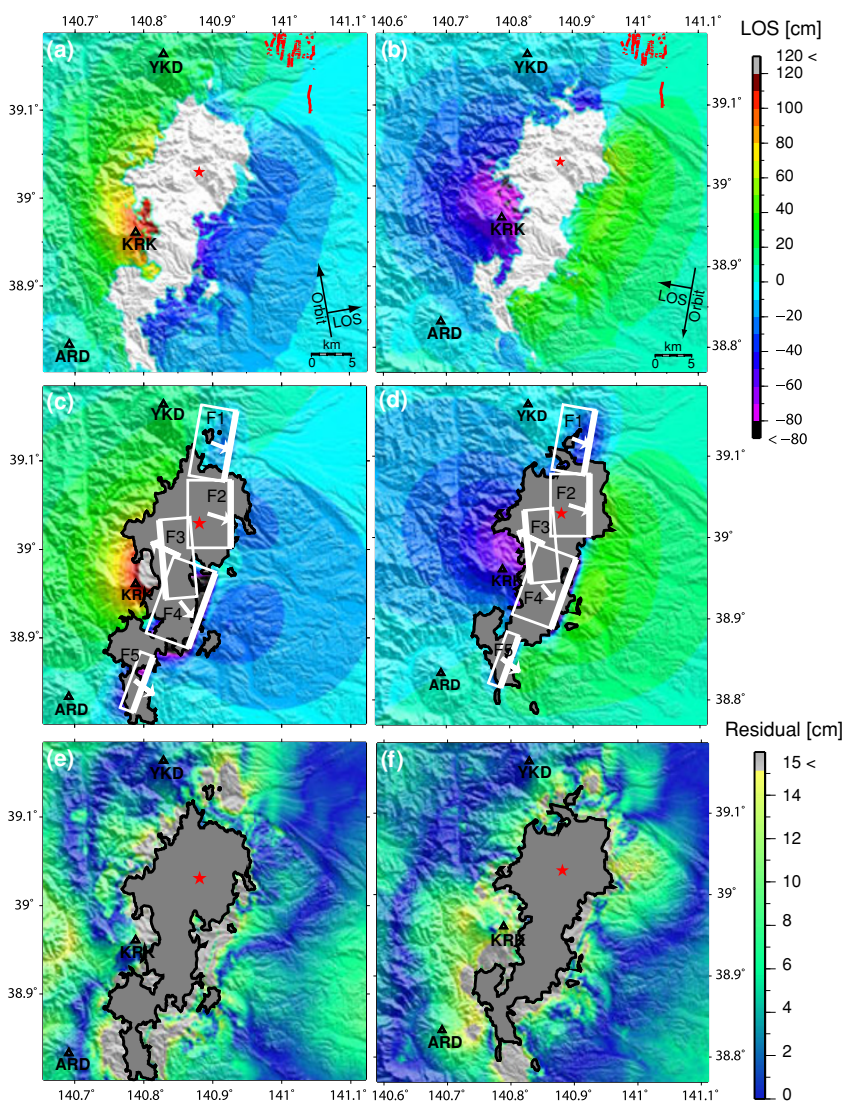

Fig. 2. (a) Observed length changes in the radar line of sight direction ( $\triangle \mathrm{LOS}$ ) over the earthquake on 14 June 2008 derived from SAR data acquired by ALOS/PALSAR ascending orbit (Path 402, frame 760-780), and (b) Descending orbit (Path 57, frame 2820-2840). The orbit and LOS directions are indicated by black arrows. (c) Simulated $\Delta$ LOS for ascending orbit, and (d) descending orbit. The fault parameters are listed in Table 1 . White frames and vectors indicate the fault positions and slip vectors projected onto the surface, respectively. Thick line indicates upper edge of each fault. (e) Residuals of the simulated $\triangle$ LOS from observations for ascending orbit and (f) descending orbit. Red star indicates the epicenter. White area of (a) and (b), and grey area of (c-e) have no InSAR data because of low coherence. Other symbols are the same as Fig. 1.

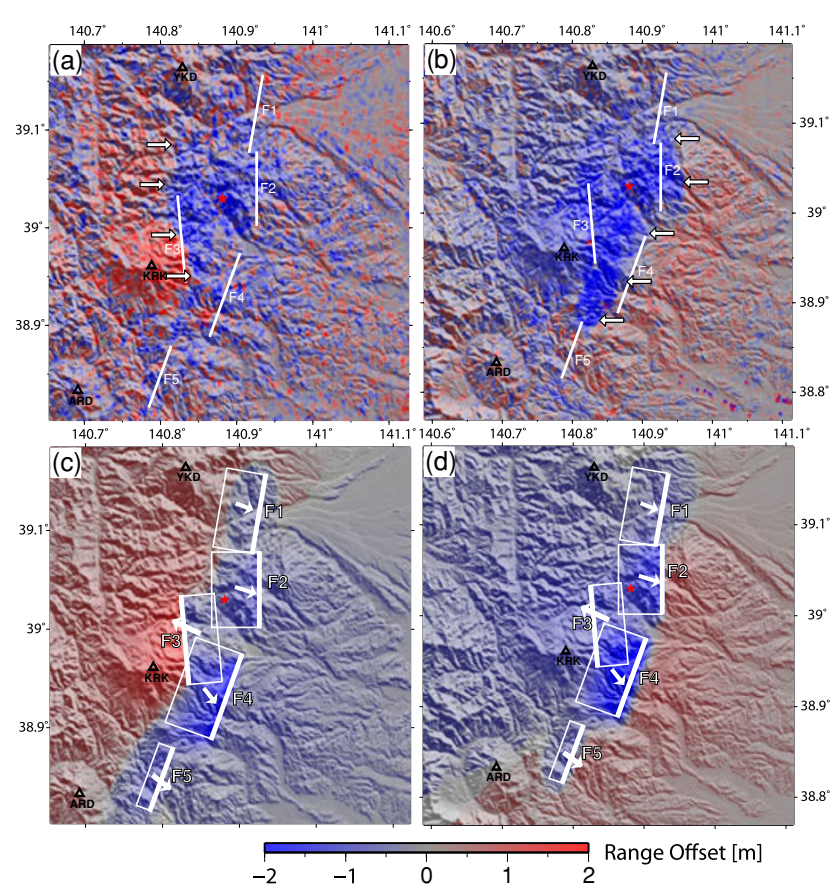

Fig. 3. Range component of the ground displacement derived by pixel matching technique for (a) ascending and (b) descending orbit, respectively. The same component calculated from our fault model for (c) ascending orbit and (d) descending orbit, respectively, are also plotted. Blue region indicates range shortening, and red indicates opposite. White arrows indicate the locations of large displacement gradient. Thick white lines indicate upper edges of the faults F1 to F5. Thin white frames in (c) and (d) indicate the surface projections of each fault. Other symbols are the same as Fig. 1. 


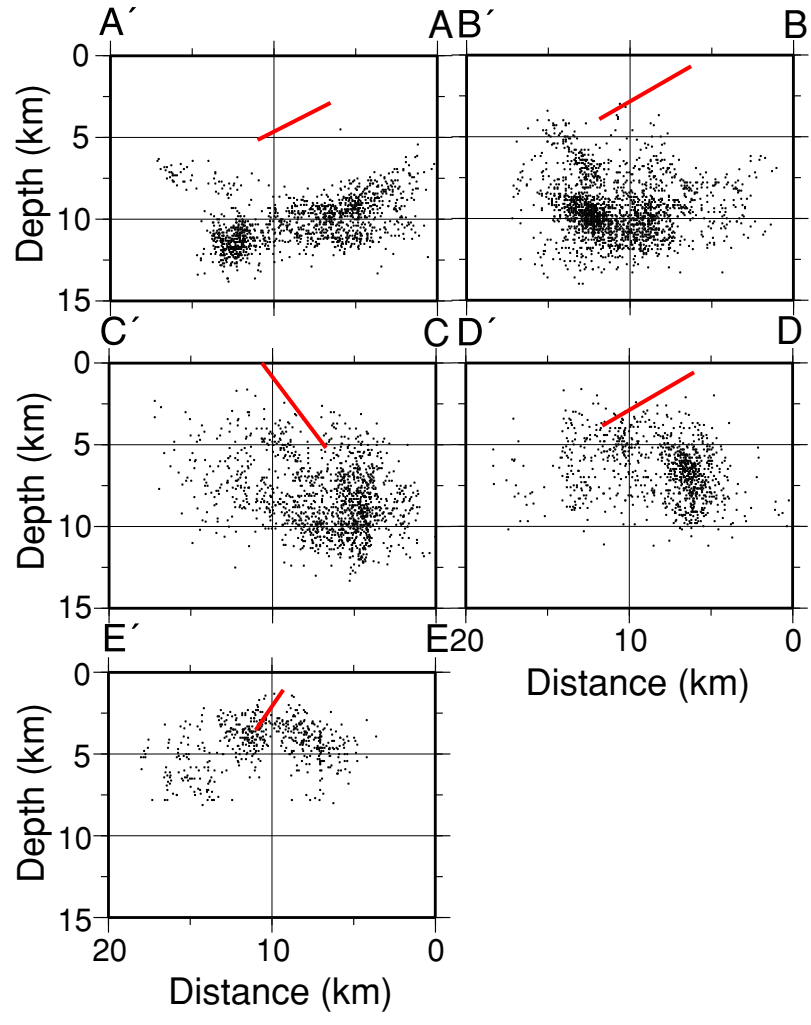

Fig. 4. Depth sections of hypocenters projected onto five section lines perpendicular to the fault segments F1 to F5, with a projection width equal to the segments length. The section lines and epicenters are indicated in Fig. 1. Black dots indicate hypocenters of earthquakes that occurred during 14 June to 18 September 2008. The hypocentral data was provided by JMA. Red lines in each figure represent the faults F1 to F5 projected onto each section.

ply a localized intensive surface deformation enhanced by a low crustal strength, as usually expected for such a geothermal area.

From InSAR and range offset field, we found that the overall crustal deformation is characterized by (1) regional WNW-ESE horizontal convergence and (2) localized large uplift along the N-S narrow band stretching along the eastern foot of Mt. Kurikoma. A large contrast in the range offset to the WNW and ESE of the incoherent area (white arrows in Fig. 3(a, b)) and two planar distributions of hypocenters (Fig. 4) attest to the conjugate faulting as proposed in our model (F2 and F3). Thus, we concluded that the rupture process of the 2008 Iwate-Miyagi Nairiku earthquake was considerably complex; the main slip is WNW dipping shallow thrust motion, but at least one ESE dipping fault motion also took place.

Such a complex faulting has been observed for shallow earthquakes in the continental crust, such as the 2004 midNiigata prefecture earthquake (Kato et al., 2006; Okada et al., 2006), and the 2007 Chuetsu-Oki earthquake (Aoki et al., 2008; Kato et al., 2008). The old caldera structure around Mt. Kurikoma would be another cause of this complexity (Umino et al., 1998; Takada and Furuya, 2009). In contrast to conventional ground-based geodetic data, the SAR data allow us to examine the entire area around the hypocenter and to illuminate complex fault geometries because of its very high spatial resolution. We leave two things for future studies which will reveal more detailed fault configuration. The first is a joint inversion of the InSAR data and the near-field range offsets. The second would be to reduce atmospheric noise with a more careful analysis of elevation-dependent atmospheric phase delay and image stackings (e.g., Cavalié et al., 2008).

Acknowledgments. PALSAR Level 1.0 data in this study are provided from PIXEL under a cooperative research contract with ERI, Univ. Tokyo and the Earthquake WG established by JAXA. The ownership of ALOS/PALSAR data belongs to METI/JAXA, Japan. The hypocenter data have been provided by JMA. This work was supported by a Grant-in-Aid for Scientific Research (B), 19340123. We acknowledge Takeshi Sagiya, Cécile Lasserre, and an anonymous referee for helpful reviews.

\section{References}

Aki, K. and P. G. Richards, Quantitative seismology, Freeman, San Francisco, 1980.

Aoki, Y., M. Furuya, and T. Kato, Coseismic deformation due to the 2007 Chuetsu-oki earthquake $\left(M_{\mathrm{w}}=6.8\right)$, Earth Planets Space, 60, 10751080, 2008.

Cavalié, O., C. Lasserre, M. P. Doin, G. Peltzer, J. Sun, X. Xu, and Z. K. Shen, Measurement of interseismic strain across the Haiyuan fault (Gansu, China), by InSAR, Earth Planet. Sci. Lett., 275, 246-257, 2008.

Kato, A., S. Sakai, N. Hirata, E. Kurashimo, T. Iidaka, T. Iwasaki, and T. Kanazawa, Imaging the seismic structure and stress field in the source region of the 2004 mid-Niigata earthquake: Structural zones of weakness and seismogenic stress concentration by ductile flow, J. Geophys. Res., 111, B08308, doi:10.1029/2005JB004016, 2006.

Kato, A., S. Sakai, E. Kurashimo, T. Igarashi, T. Iidaka, N. Hirata, T. Iwasaki, T. Kanazawa, and Group for the aftershock observations of the 2007 Niigataken Chuetsu-oki Earthquake, Imaging heterogeneous velocity structures and complex aftershock distributions in the source region of the 2007 Niigataken Chuetsu-oki Earthquake by a dense seismic observation, Earth Planets Space, 60, 1111-1116, 2008.

Michel, R., J. P. Avouac, and J. Taboury, Measuring ground displacements from SAR amplitude images: application to the Landers earthquake, Geophys. Res. Lett., 26, 875-878, 1999.

Nakata, T. and T. Imaizumi (ed.), Digital active fault map of Japan, University of Tokyo Press, Tokyo, 2002.

Okada, T., T. Yaginuma, N. Umino, T. Matsuzawa, A. Hasegawa, H. Zhang, and C. H. Thurber, Detailed imaging of the fault planes of the 2004 Niigata-Chuetsu, central Japan, earthquake sequenced by doubledifference tomography, Earth Planet. Sci. Lett., 244, 32-43, 2006.

Okada, T., N. Umino, A. Hasegawa, and Group for the aftershock observations of the Iwate-Miyagi Nairiku Earthquake in 2008, http://wwwsoc.nii.ac.jp/ssj/for_member/NL/v20n4/04.html, SSJ Newsletter, 20(4), 8-10, 2008 (in Japanese).

Okada, Y., Internal deformation due to shear and tensile faults in a halfspace, Bull. Seismol. Soc. Am., 82, 1018-1040, 1992.

Pathier, E., E. J. Fielding, T. J. Wright, R. Walker, B. E. Parsons, and S. Hensley, Displacement field and slip distribution of the 2005 Kashmir earthquake from SAR imagery, Geophys. Res. Lett., 33, L20310, doi:10.1029/2006GL027193, 2006.

Takada, Y. and M. Furuya, Aseismic slip during the 1996 earthquake swarm in and around the Onikobe geothermal area, NE Japan, Earth Planet. Sci. Lett., 2009 (in revision).

Tobita, M., M. Murakami, H. Nakagawa, H. Yarai, S. Fujiwara, and P. A. Rosen, 3-D surface deformation of the 2000 Usu eruption measured by matching of SAR images, Geophys. Res. Lett., 28, 4291-4294, 2001.

Umino, N., T. Matsuzawa, S. Hori, A. Nakamura, A. Yamamoto, A. Hasegawa, and T. Yoshida, 1996 Onikobe earthquakes and their relation to crustal structure, J. Seismol. Soc. Jpn., 51, 253-264, 1998 (in Japanese with English abstract).

Wegmüler, U. and C. L. Werner, Gamma SAR processor and interferometry software, in Proc. the 3rd ERS Symposium, ESA, SP-414, 1686$1692,1997$.

Y. Takada (e-mail: ytakada@mail.sci.hokudai.ac.jp), T. Kobayashi, M. Furuya, and M. Murakami 